Encontros Bibli: revista eletrônica de biblioteconomia e ciência da informação, v. 17, n. esp.1, p. 67-86, 2012. ISSN 1518-2924. DOI: 10.5007/1518-2924.2012v17nesp1p67

\title{
O CONTEXTO SOCIOCOGNITIVO DO INDEXADOR NO PROCESSO DE REPRESENTAÇÃO TEMÁTICA DA INFORMAÇÃO ${ }^{\mathrm{i}}$
}

\author{
Vera Regina Casari Boccato ${ }^{\text {ii }}$
}

\begin{abstract}
Resumo: O foco deste estudo é a interdisciplinaridade entre as vertentes cognitivas e a Ciência da Informação, com destaque para a Psicologia Cognitiva, como campo científico colaborativo no delineamento do contexto sociocognitivo do indexador, visto como elemento norteador na representação temática adequada para a recuperação por assunto em catálogos online de áreas científicas especializadas. Os resultados demonstram que o contexto sociocognitivo do bibliotecário indexador é um elemento de suma importância na adequada representação da informação para a busca por assunto em catálogos online. Conclui-se que as visões holística e coletiva do bibliotecário indexador são privilegiadas, contribuintes para a definição de um tratamento temático da informação e na modelagem de sistemas de recuperação da informação. A partir dessa concepção, a área de Ciência da Informação volta-se para uma dimensão teórica focada por abordagens interpretativas, centradas no aspecto semântico e no contexto social da informação, do bibliotecário indexador e do usuário.
\end{abstract}

Palavras-chave: Representação temática. Linguagem documental. Indexador. Contexto sociocognitivo. Catálogo online. Áreas científicas especializadas.

\section{THE SOCIOCOGNITIVE CONTEXT OF INDEXER IN THE PROCESS OF INFORMATION THEMATIC REPRESENTATION}

\begin{abstract}
The focus of this study is the interdisciplinary between the cognitive aspects and Information Science, with emphasis on Cognitive Psychology, and scientific field in the collaborative design of sociocognitive context of the indexer, seen as a guiding element in the thematic representation suitable for recovery by subject in online catalogs of specialized scientific areas. The results show that the sociocognitive context of the indexer is an element of great importance for the proper information representation to search for the subject in online catalogs. It is concluded that the holistic and collective visions of the indexer are privileged, contributors to the definition of a thematic treatment of information and modeling of information retrieval systems. Based on this concept, the Information Science area turns to a theoretical dimension focused on interpretive approaches, focusing on semantics and social context of information, the indexer and user.
\end{abstract}

Keywords: Thematic representation. Indexing language. Indexer. Sociocognitive context. Online catalogue. Specialized scientific areas.

\footnotetext{
${ }^{\mathrm{i}}$ Parte desse artigo foi extraído da tese de doutorado da autora intitulada Avaliação do uso de linguagem documentária em catálogos coletivos de bibliotecas universitárias: um estudo sociocognitivo com protocolo verbal, sob a orientação da Profa. Dra. Mariângela Spotti Lopes Fujita.

${ }^{\text {ii } U n i v e r s i d a d e ~ F e d e r a l ~ d e ~ S a ̃ o ~ C a r l o s ~(D C I-U F S C a r) . ~ v b c c a t o @ u f s c a r . b r ~}$
} 


\section{INTRODUÇÃO}

Numa abordagem inicial sobre os espaços interdisciplinares da Ciência da Informação verificamos que os estudos sobre a cognição humana estão estritamente associados à Filosofia, a partir das concepções de Sócrates e Platão sobre o conhecimento humano ser “inerente" às Ciências Exatas e à Matemática, seguido por Aristóteles com sua tese sobre o conhecimento humano ser "adquirido", refutando as idéias anteriores apresentadas.

O Renascimento e o Iluminismo trouxeram filósofos como Descartes, Locke e Kant para o centro das discussões sobre o conhecimento humano, dissertando sobre teorias e questões empíricas sobre a sua gênese. A partir do final do século XIX, assistimos a uma proliferação de teorias sobre essa questão, culminando no surgimento de novas áreas como a Linguística, a Antropologia, a Sociologia, a Neurociências, a Inteligência Artificial, a Ciência Cognitiva e a Psicologia, todas com propostas de realizarem estudos sobre a natureza da mente humana.

No contexto da Ciência da Informação, Ingwersen (1992) investiga a área sob a perspectiva de uma ciência cognitiva influenciada por diversos campos científicos, enfatizando sua maior intersecção com a Linguística, Inteligência Artificial, Ciência Cognitiva e a Psicologia, sinalizando novos desafios para a área referente a mudanças sociais, revolução tecnológica e a ampliação dos espaços interdisciplinares.

Diante disso, apontamos como ponto focal deste estudo a interdisciplinaridade entre as vertentes cognitivas e a Ciência da Informação, com destaque para a Psicologia Cognitiva como campo científico colaborativo no delineamento do contexto sociocognitivo do indexador, visto como elemento norteador na representação temática adequada para a recuperação por assunto em catálogos online de áreas científicas especializadas.

\section{AS DIMENSÕES COGNITIVAS DA REPRESENTAÇÃO TEMÁTICA DA INFORMAÇÃO EM CIÊNCIA DA INFORMAÇÃO}

A Psicologia Cognitiva, ramo da Psicologia, preocupa-se com os estudos sobre a percepção, o pensamento e a memória, com o intuito de analisar e explicar como os indivíduos observam e percebem os fatos, as coisas e como utilizam esse conhecimento 
adquirido para a realização de diversas funções e atividades como raciocinar, ler, escrever, solucionar problemas, falar, lembrar, entre outras.

Para Sternberg (2008, p. 22) ela é a ciência que "trata do modo como as pessoas percebem, aprendem, recordam e pensam sobre a informação". Possuindo diferentes correntes teóricas, focaliza questões da gênese do conhecimento humano, vinculadas ao domínio da linguagem; psicologia do desenvolvimento; pensamento e formação de conceitos; estudos sobre o processamento da informação; inteligência humana e inteligência artificial, porém detendo em sua concepção inicial os aspectos da "representatividade", "computador" e "desvinculação da emoção, do contexto, da cultura e da história".

Dentre as correntes teóricas da Psicologia Cognitiva, destacamos a corrente que arrola os estudos sobre o "processamento da informação", processo esse onde ocorre a "cognição" (a ação do indivíduo "pensar") por meio de uma sequência de fases - memória sensorial, memória operacional e memória permanente - que constituem a memória humana.

Neves (2011, p. 29) expõe que a “[...] cognição refere-se a um tipo específico de representação dos objetos e fatos (representações proposicionais) ou qualquer tipo de representação da informação proveniente do meio".

No processo de aprendizagem humana a informação é recebida pela memória sensorial, é processada e codificada pela memória operacional e armazenada por uma memória permanente sob a forma de modelos mentais, à semelhança da memória de um computador - constatação essa que justifica o computador ser um dos aspectos fundamentais nos trabalhos da Psicologia Cognitiva. Os modelos mentais são representações mentais, isto é, uma forma analógica do conhecimento, onde são combinadas informações e suas interações constituindo-se, dessa forma, redes de assuntos. Explicitamente, os modelos mentais são as formas de como os indivíduos percebem o mundo (STERNBERG, 2008).

Complementando, Bernard (1995, p. 60-61) relata que o mais importante da psicologia de processamento de informação é o tripé de classificação do conhecimento humano caracterizado pelo conhecimento declarativo, pelo procedimental e pelo metacognitivo, a saber:

- conhecimento declarativo ou representacional: refere-se ao "saber" das coisas, do mundo que nos rodeia e o que fazemos para obter uma representação da informação na mente que nos permita compreendê-la, armazená-la e, posteriormente, utilizá-la. Esse conhecimento está acumulado na memória a longo prazo (memória sensorial), e é representado sob a forma de esquemas, redes, mapas conceituais, etc., 
que equivalem a conjuntos de dados que são unidos por vínculos lógicos de distintas naturezas. Este tipo de conhecimento traduz os dados através de uma representação significativa interna, utilizando-se dos dois códigos principais ou básicos de pensamento: o código verbal, que processa a informação simbólica e sequencial, e o código gráfico, que se ocupa do figurativo e estrutural;

- conhecimento procedimental: ocupa-se de como utilizamos a informação, como operamos com ela e dos procedimentos que empregamos para alcançar os conhecimentos e recuperá-los quando necessitamos utilizá-los. O conhecimento procedimental trabalha com a memória a curto prazo (memória operacional) e utiliza-se de dois tipos principais de procedimentos : os heurísticos - o que assegura a eficácia do objetivo pretendido - e os algoritmos - conjunto de regras que garante a obtenção de um objetivo;

- conhecimento metacognitivo: refere-se ao o que conhecemos sobre o nosso próprio modo de pensar; a metacognição (memória permanente) estuda o conhecimento que o sujeito tem de si e de seu próprio sistema de pensamento referentes aos seus recursos mentais, suas zonas fortes e deficientes - com que condições pode obter êxito na realização de tarefas, o que deve fazer para prognosticar possíveis fracassos pessoais e como planejar seus esforços para obter rentabilidade, entre outras ações.

Diante do exposto, observamos que a interdisciplinaridade entre Psicologia Cognitiva e a Ciência da Informação dá-se com a questão do "processamento da informação" e da "cognição", refletindo o discurso sobre a comunicação ordenada do pensamento ou o poder de pensar logicamente.

Esse cenário pode ser comprovado quando revitalizamos Bush (1945) expondo que "a finalidade da Ciência da Informação é possibilitar a comunicação de informações entre seres humanos", questão essa vivenciada, principalmente, a partir da década de 1970, com os estudos teóricos e aplicados desenvolvidos por Ingwersen (2002) sobre a Teoria Cognitiva da Recuperação da Informação, caracterizados pelos modelos conceituais do paradigma cognitivo (recuperação da informação centrada no usuário), correspondente às questões epistêmicas da área de Ciência da Informação.

Segundo Fujita (2005, p. 30), a abordagem cognitiva refere-se [...] aos estudos que consideram o conhecimento humano, tanto sob o ponto de vista de processamento quanto de 
representação, como parâmetro para a análise e elaboração de teorias e metodologias [...]. Para Neves (2006, p. 42), o processamento da informação é presenciado na [...] "recuperação ou no processamento técnico da informação", agregando [...] "todas as ações realizadas pelos profissionais da informação envolvendo atividades cognitivas".

Explicitamente, no contexto da área de Organização e Representação do Conhecimento em Ciência da Informação, a "cognição" e o "processamento da informação" são contemplados nos estudos e práticas desenvolvidos sobre os processos documentais leitura, análise - com a identificação e seleção de conceitos, condensação e representação documental, além da recuperação da informação, no tratamento, acesso e disponibilização da informação de áreas científicas especializadas em catálogos coletivos online.

No processo de indexação, a análise e identificação do conteúdo são realizadas por meio da cognição, por isso ela não é um processo sistemático de etapas consecutivas, mas é um processamento mental de informações, que depende de conhecimento prévio e é composta de habilidades operatórias de pensamento (OLIVEIRA, 2005).

Neves $(2006$, p. 42) destaca a indexação enquanto "[...] processo intelectual que tem por base a compreensão do texto e a representação do documento [...]” a qual está “[...] intimamente ligada à abordagem do processamento da informação na psicologia cognitiva".

Observamos, portanto, que na indexação, a "cognição" e o "processamento da informação" estão presentes no momento da leitura documental, fase mais importante da análise de assunto. Essa, realizada pelo bibliotecário indexador - leitor profissional - deve refletir os objetivos da indexação, isto é, num primeiro momento o bibliotecário indexador realizará a identificação e seleção dos assuntos contidos no documento para, num segundo momento, representá-los por meio da utilização de uma linguagem documental.

Sobre isso, Fujita e Rubi (2006) relatam que,

\footnotetext{
o indexador, visto como leitor, é considerado sob a perspectiva da psicologia cognitiva, pois, ao ler aciona, como em qualquer outro indivíduo, o processamento humano de informações, realizado com a memória de curto prazo (input visual), a memória de longo prazo (esquemas e conhecimento prévio) e as habilidades operatórias de pensamento (análise e síntese). Visto como leitor profissional é considerado a partir da perspectiva de seu contexto, atuação e formação profissional.
}

- Nessa linha teórica do paradigma cognitivo, concentram-se também as pesquisas desenvolvidas por Fujita, Nardi e Santos (1998), Naves (2001) e Neves (2006) que tratam com profundidade o tema de leitura documental, focalizando o bibliotecário indexador experiente na realização da indexação de textos científicos, com o propósito de observar sua metacognição e estratégias de leitura. Nesse referido paradigma, a preocupação primária 
dessas pesquisas foi a de conhecer os modelos mentais, conduzindo-se o próprio usuário e o seu contexto sociocultural a uma posição secundária.

Dessa forma, entendemos que os objetivos da leitura documental e do bibliotecário indexador são diferentes com relação à leitura e ao leitor comum. A leitura documental, praticada pelo bibliotecário indexador, constitui seu contexto de trabalho e, portanto, condiciona suas estratégias. Portanto, a leitura documental é uma atividade interativa que, de acordo com Fujita (2004), deve ser vista sob três variáveis interligadas, isto é, o leitor, o texto e o contexto, a saber:

1. o leitor: corresponde ao bibliotecário indexador - leitor profissional -. Este realiza uma leitura objetiva visando à realização da indexação. Ele deve compreender o texto e não interpretá-lo com o intuito da identificação e seleção dos conceitos para sua representação. No momento dessa atividade de leitura, o bibliotecário indexador recorre aos seus conhecimentos prévios como a própria linguagem documental utilizada; seus recursos intelectuais como o conhecimento linguístico e o seu conhecimento de mundo em que está inserido;

2. texto: o texto é representado pelo próprio documento que está sendo indexado. No âmbito da biblioteca universitária, os documentos são representativos dos conteúdos de áreas científicas especializadas;

3. contexto: este se refere ao meio físico, social e psicológico em que o bibliotecário indexador está inserido. Giasson (1993) identifica esses contextos como o físico, o psicológico e o social, apresentados por Boccato e Fujita (2006) e exemplificados por nós, no âmbito deste estudo, da seguinte forma:

- físico: todas as condições materiais em que se desenrola a leitura. Compreende as instalações físicas da biblioteca universitária em que o bibliotecário atua profissionalmente como indexador, os equipamentos utilizados para o desenvolvimento dessa atividade sendo o microcomputador e outros recursos físicos necessários para tal;

- psicológico: condições contextuais próprias do leitor: interesse pelo texto, motivação, intenção de leitura. Esse contexto contempla o estado psicológico de como o bibliotecário indexador está inserido/relacionado com o seu meio, considerando-se também sua saúde física e emocional como elementos de influência para o êxito de uma leitura documental bem sucedida, e 
consequentemente, adequada na recuperação precisa da informação em catálogos coletivos online de áreas científicas especializadas de bibliotecas universitárias;

- social (sociocognitivo): todas as formas de interação que podem produzir-se no decurso da atividade. Refere-se ao usuário que irá utilizar o catálogo coletivo online para a realização de suas buscas bibliográficas e os instrumentos de trabalho utilizados pelo bibliotecário indexador, exemplificados pelo manual de indexação. A política de indexação também influencia a leitura documental, pois os objetivos da leitura estão vinculados a uma política de indexação definida e utilizada pelo sistema.

Verificamos, portanto, que todo o processo de leitura documental está intimamente relacionado com o seu contexto, fator esse determinante para a realização da indexação e, nessa vertente, os postulados teóricos advindos do paradigma social alicerçam as bases epistêmicas do contexto sociocognitivo que enfatizam a interação individual e do ambiente social/organizacional nos processos de indexação e recuperação da informação.

O paradigma social estrutura-se mediante uma crítica de Frohmann (1990) ao paradigma cognitivo, por esse não considerar o processo social de construção dos processos informacionais. Para o autor (Frohmann, 1990), a Ciência da Informação é uma prática social e sua visão ótica sob a perspectiva cognitiva restringe sua abrangência.

Sobre isso, Jacob e Shaw (1998) relatam que a perspectiva sociocognitiva presencia a integração do ponto de vista cognitivo a uma abordagem mais sociológica ou sociocultural, com a mudança de foco das estruturas de conhecimento individual para os domínios discursivos, representados pelas comunidades de produção de conhecimento, compartilhamento de conhecimento e consumo de conhecimento.

Olson e Boll (2001), pesquisadores nos estudos de análise de assuntos em catálogos online, enfocam as teorias construtivistas e construcionistas para fundamentarem as teorias preconizadas pelo paradigma social.

O construtivismo é uma das correntes científicas da Psicologia, mais especificamente aplicada à Educação, apresentada por Lev Semenovich Vygotsky, onde as ações integradas entre o indivíduo e o meio ambiente físico e social em que vive são fatores determinantes para a concepção da inteligência humana. Essa teoria defende que, durante o processo de ensinoaprendizagem, o indivíduo em contato com uma pessoa mais experiente e com o quadro histórico-cultural em que se relaciona, ativa esquemas processuais cognitivos ou 
comportamentais, desenvolvendo novas potencialidades, num processo contínuo de aquisição de conhecimento. (VYGOTSKY, 1989).

A abordagem construcionista do matemático Seymour Papert retrata que os indivíduos adquirem um melhor nível de aprendizado não pelo fato dos professores terem encontrado melhores maneiras e recursos de instruí-los, mas por lhes terem proporcionado melhores oportunidades de construir (PAPERT, 1990, FINO, 2008).

Nesse sentido, observa-se a existência de uma confluência entre as teorias construtivista de Vygotsky e o construcionismo de Papert presentes também no contexto do paradigma social construcionista apresentado por Olson e Boll (2001), na realização da tarefa da recuperação da informação. Os usuários, com suas necessidades de informação, compartilham-na com o intermediário humano (profissional da informação) que lhe fornece condições apropriadas no atendimento, fornecendo subsídios técnico-operacionais para a busca da informação, possibilitando-lhes construir a sua própria maneira de buscar e de adquirir esse novo conhecimento, aliando os aspectos econômicos, sociais e culturais integrantes do ponto de vista de mundo que os norteiam para tais realizações.

O usuário associado com a assistência responsável do bibliotecário no desenvolvimento da tarefa de assisti-lo na busca de informações pertinentes à sua pesquisa, identifica-se como um usuário consciente do seu real saber e querer no momento da formulação da questão de pesquisa. Desse modo, ele passa por diferentes estágios comportamentais e de (re)organização de informações, necessários no processo de busca, recuperação e aquisição de conhecimento.

Para Capurro (2003), o paradigma social é visto como uma abordagem sociocognitiva onde, a partir da análise de domínios, busca-se favorecer a "Gestão do Conhecimento", levando-se em consideração o conhecimento compartilhado por uma comunidade ou grupo.

Hjørland e Albreschtsen (1995) expõem que a área de Ciência da Informação deve assumir os preceitos das ciências sociais em seus postulados teóricos, tendo em vista que o seu objeto de estudo é socialmente produzido, transferido e utilizado. Os referidos autores propõem o uso da Análise de Domínio, proveniente da Ciência da Computação, como abordagem à área que destaca as dimensões sociais, históricas e culturais da informação como pré-condições para o entendimento da informação.

Entre os principais predecessores da análise de domínio em Ciência da Informação destacamos Henry Evelyn Bliss (1870-1955), que procurava o consenso da comunidade científica, pois, ao fazer isso, acreditava ser possível identificar e mapear a estrutura básica 
permanente da área de assunto e Shiyali Ramamrita Ranganathan com a criação da Teoria de Classificação Facetada como um método de análise classificatório de disciplinas de assunto, isto é, um tipo de análise de domínio (HJØRLAND; ALBRECHTSEN, 1995).

Por sua vez, a análise de domínio é vista pelo seu principal teórico, Birger Hjørland (2002), como uma unidade de análise formada pelos campos coletivos de conhecimento ou domínios de conhecimento, de acordo com suas "comunidades discursivas". O autor identifica uma "comunidade discursiva" como um espaço onde ocorre um processo de comunicação ordenado e delimitado, caracterizado por serem científicas, acadêmicas ou profissionalis, com estruturas de comunicação e publicação, tipos de documentos, terminologia específica e estruturas informacionais únicas, e todas com estrutura e organização do conhecimento, padrões de cooperação, formas de linguagem e comunicação, sistemas de informação, literatura e sua distribuição e critérios de relevância.

Observamos, nesse sentido, que os sistemas de organização do conhecimento, os conceitos e suas relações semânticas, as estruturas de informação, as necessidades de informação e os critérios de relevância são "moldados" em comunidades discursivas. Identificamos, dessa forma, a biblioteca universitária como uma comunidade discursiva, desempenhando um importante papel social, atuando como gestora e disseminadora das informações e dos documentos produzidos por pesquisas científicas geradas pela universidade, tendo como interlocutores desses processos os bibliotecários indexadores e os usuários, por meio da utilização da linguagem documental adotada pelo sistema como um canal de comunicação para a representação e recuperação da informação.

A abordagem da análise de domínio proposta por Hjørland (2002) é baseada nos estudos e nas concepções de John Dewey, Lev Semenovich Vygotsky e na Teoria da Atividade desenvolvida por Alexey Leontiev ${ }^{3}$, que fornece uma estrutura pragmática para o estudo da cognição e do comportamento humano. Nesse foco de análise, o conhecimento é visto como resultado da interação do sujeito com o meio, como estrutura criada culturalmente e como produto histórico da atividade humana ligada, não às mentes dos indivíduos, mas à prática social. O conhecimento é, portanto, ao mesmo tempo explícito, no que pode ser

\footnotetext{
${ }^{3}$ Alexey Leontiev desenvolveu a Teoria da Atividade - desdobramento da Teoria Sócio-Histórica idealizada por Vygotsky - preconizando que "[...] os homens são determinados por suas atividades, estas são condicionadas sócio-historicamente e realizadas a partir de motivos-fins, ações-procedimentos e objetos, bem como com as formas de organização" [CASTRO NETO, M. Da teoria da atividade a atividade docente em ambientes virtuais de apoio à aprendizagem. 2006. f. 32. Tese (Doutorado em Engenharia de Produção, Área de Mídia e Conhecimento) - Universidade Federal de Santa Catarina, Florianópolis].
} 
comunicado através da linguagem e implícito, ou tácito, no que pode ser embutido dentro de atividades em particular (JACOB; SHAW, 1998; NASCIMENTO, 2006).

Hjørland (2002) orienta para que a análise de domínio seja combinada com as pesquisas tradicionais da Ciência da Informação, fortalecendo a identidade do campo científico e a importância do relacionamento entre as pesquisas teóricas e práticas . Para tanto, o autor descreve onze abordagens, entre tradicionais ${ }^{4}$ e inovadoras, para a análise de domínio na Ciência da Informação, a saber: 1) produção de guias de literatura e portais temáticos; 2) construções de classificações especializadas e tesauros; 3) indexação e recuperação especializadas; 4) estudos empíricos de usuários; 5) estudos bibliométricos; 6) estudos históricos; 7) estudos do gênero e sobre documentos; 8) estudos críticos e epistemológicos; 9) estudos terminológicos, linguagens para propósitos especiais, bases de dados semânticas e estudos do discurso; 10) estruturas e instituições em comunicações científicas; 11) cognição científica, conhecimento especializado e inteligência artificial.

Dentre as onze abordagens de análise de domínio para a Ciência da Informação, verificamos que a nossa pesquisa encontra-se representada nas abordagens de números 2) construções especiais de classificações e tesauros que se referem aos vocabulários controlados especiais, às estruturas lógicas de categorias e conceitos de um documento ou domínio e às relações semânticas entre os conceitos; e 3) indexação e recuperação especializadas que trata da organização e recuperação de conteúdos documentais.

Portanto, dentre os pressupostos teóricos apresentados, destacamos principalmente as concepções de Hjørland (2002) sobre o contexto sociocognitivo visto pela perspectiva da adoção de uma "abordagem metodológica coletivística", que incorpora investigação psicológica do individual dentro de uma perspectiva sociocultural e histórica mais abrangente, fixando o interno/individual dentro do externo/ambiente e, desse modo, integrando os vários níveis de investigação para alcance de sistemas de representação e recuperação verdadeiramente efetivos. Pela perspectiva sociocognitiva, muda-se a atenção de estruturas de conhecimento individual para domínios discursivos, enfocando as comunidades de produção de conhecimento, compartilhamento de conhecimento e consumo de conhecimento e, dessa forma, os domínios discursivos e as comunidades de conhecimento são a unidade apropriada de estudo na Ciência da Informação (JACOB; SHAW, 1998).

\footnotetext{
${ }^{4}$ As abordagens tradicionais: 1) produção de guias de literatura e portais temáticos; 2) construções de classificações especializadas e tesauros , 3) indexação e recuperação especializadas; e 5) estudos bibliométricos. (CAMPOS, L. F. de B.; VENÃNCIO, L. S. O objeto de estudo da Ciência da Informação: a morte do indivíduo. Informação \& Informação, Londrina, v.11, n. 1, jan./jun. 2006). 
Nesse âmbito, o processo documental caracterizado pela indexação é colaborativo no delineamento do contexto sociocognitivo do indexador em bibliotecas universitárias, à medida que essa atividade envolve os modelos mentais desse sujeito inserido em seu ambiente sóciocultural, conforme apresentado na subseção subsequente.

\section{O CONTEXTO SOCIOCOGNITIVO DO INDEXADOR}

Antes de caracterizarmos o contexto sociocognitivo do bibliotecário indexador em bibliotecas universitárias, torna-se fundamental discutirmos sobre a indexação e as ações e operações que envolvem esse processo no contexto do paradigma social.

Dessa maneira, em consonância aos fundamentos teóricos apresentados sobre o paradigma social e no âmbito da indexação e dos sistemas de organização do conhecimento, Jacob e Shaw (1998, p. 135) expõem o relato de Shera (1965) sobre ser inevitável que a investigação cognitiva se volte para a natureza das estruturas de conhecimento compartilhadas e o papel da linguagem para o processo de comunicação refletindo sobre o desenvolvimento, organização e manutenção de linguagens representacionais e atividades subsequentes de indexação e classificação.

Frohmann (1990) relata que a indexação consiste em dois distintos níveis de operações: a primeira envolve a representação implícita ou explícita do documento por termos de indexação, e o segundo a transição dos termos da indexação para o léxico de um vocabulário controlado possuidor de relações semânticas e sintáticas provenientes da linguagem de indexação. O primeiro nível é caracterizado por ser uma operação mental associada ao desempenho do bibliotecário indexador e que a construção de regras de indexação não deve ser baseada somente nos processos cognitivos residentes na mente, mas em regras socialmente construídas por indicadores, pois a aplicação correta de um termo significa que este deve estar de acordo com as regras estabelecidas pelo contexto de sua aplicação.

$\mathrm{Na}$ abordagem de Hjørland (2002), a indexação é um processamento intelectual que depende da cognição; e o domínio dos contextos físico, psicológico e sociocognitivo é necessário para que o bibliotecário indexador realize a identificação e a seleção de conceitos na concepção orientada para o conteúdo e para a demanda. Além disso, enfatiza que os estudos empíricos de usuários podem colaborar com os bibliotecários na compreensão das 
necessidades informacionais, uma vez que, na verdade, eles devem ser experientes em organização e busca de informação.

O contexto sociocognitivo é abordado também nos trabalhos de Fujita (2004), Rubi et al. (2007), Fujita, Rubi e Boccato (2009), Boccato e Fujita (2011, 2012) arrolando estudos que envolvem os bibliotecários indexadores e usuários como sujeitos de pesquisas, possibilitando verificar as preferências e analisar as percepções, identificando as dificuldades e os procedimentos utilizados na representação e no uso de serviços de recuperação da informação, para compará-los com resultados obtidos por outras pesquisas que visam à compreensão do contexto.

Dessa forma, verificamos que os estudos de Belkin (1980) e Ingwersen (2002), sobre a adoção de modelos cognitivos individualistas para a construção de sistemas de recuperação da informação foram revistos e criticados pelos estudos de Frohman (1990), Hjørland (2002), Jacob e Shaw (1998), Fujita (2004), Rubi et al. (2007), Fujita, Rubi e Boccato (2009), Boccato e Fujita $(2011,2012)$ que consideram o paradigma social como dimensão teóricometodológica na adoção de um método qualitativo com abordagem coletivística, isto é, uma metodologia envolvendo os processos cognitivos do indivíduo associados aos contextos sociais, culturais e históricos, com vistas a subsidiar investigações sobre a construção e avaliação de sistemas de organização do conhecimento e de recuperação da informação mais representativos da realidade dos bibliotecários indexadores e usuários.

Assim, entendemos que o contexto sociocognitivo visa à representação e a recuperação da informação por meio da visão do indivíduo inserido no seu contexto sóciocultural-histórico, partindo do pressuposto de que a necessidade de informação do usuário é construída de fora para dentro, isto é, o seu meio influenciando e contribuindo para a construção dessa necessidade, que será representada por seus modelos mentais associados a sua concepção de mundo, refletindo no seu interesse real de informação.

Portanto, sob nosso ponto de vista, ao contrário da visão cognitiva que valoriza apenas os modelos mentais do indivíduo, a visão social considera o contexto uma variável imprescindível para a construção de um modelo sociocognitivo, refletindo na construção do próprio conhecimento e, consequentemente, na informação - com valor social agregado -, acentuando a gênese da área de Ciência da Informação como uma ciência social. Notamos, dessa forma, a aproximação dos aspectos cognitivos com os aspectos sociais, revelando uma 
postura e uma perspectiva pragmática ${ }^{5}$ de investigações científicas embasadas por fundamentos teóricos e metodológicos advindos da Ciência da Informação e de suas áreas interdisciplinares.

O contexto realiza a intermediação entre a situação real dentro da biblioteca -norteada pelas concepções de análise de assunto utilizadas pelo bibliotecário indexador - e o sistema linguístico - linguagem documental adotada pelo sistema -, caracterizado pela representação dos documentos indexados.

Sobre as concepções de análise de assuntos, Albrechtsen (1993, p. 220-222) apresenta três concepções que estão relacionadas com os objetivos institucionais e, consequentemente, com os objetivos do próprio sistema de recuperação da informação.

Segundo a autora (Albrechtsen, 1993, p. 220-222), a prática por uma concepção de assunto pelo bibliotecário indexador está intimamente relacionada aos objetivos estabelecidos, explicitados pela política de indexação do sistema. Essas concepções de análise, que acreditamos afetar o desempenho do bibliotecário indexador, são classificadas em: concepção simplista, concepção orientada pelo conteúdo e concepção orientada para a demanda, e destacadas por Boccato e Fujita (2006), a saber:

- $\quad$ concepção simplista (simplist conception of subject analysis): os assuntos são vistos como entidades objetivas absolutas que podem ser derivadas de abstrações linguísticas de documentos, usando métodos estatísticos de indexação (dados que podem ser somados), [...] possibilitando a realização da indexação automática;

- $\quad$ concepção orientada para o conteúdo (content-oriented conception of subject analysis): envolve uma interpretação do conteúdo do documento que vai além da estrutura léxica e, às vezes, gramatical do texto, ou seja, envolve aspectos mais complexos que o processo da concepção simplista". A idéia fundamental dessa concepção é que um documento pode também transmitir uma informação implícita que não está diretamente expressa pelo autor, mas que necessita ser compreendida e interpretada pelo leitor humano [...];

- $\quad$ concepção orientada para a demanda (requirements-oriented conception of subject analysis): envolve os dados do assunto como instrumentos de transferência do conhecimento, apontando um encontro pragmático da informação ou do

\footnotetext{
${ }^{5}$ Pela perspectiva pragmática, Hjorland e Albrechsen (1995) consideram que a informação é ação e seu significado é o uso dessa ação em cada contexto, em cada comunidade discursiva ou domínio.
} 
conhecimento. De acordo com esta concepção, os documentos são criados para comunicar o conhecimento, e dados do assunto precisam funcionar como um instrumento para mediá-lo, sendo visível para usuários potenciais [...].

Desse modo, observamos que o contexto é uma variável importante, pois pode agregar valores em determinados termos, podendo estes assumir novos significados, apenas mudando o seu contexto de análise. Portanto, ele deve ser visto como um elemento norteador no desempenho do bibliotecário indexador, pois estabelece e delimita as funções desse profissional dentro da biblioteca, de modo que ele possa exercer suas atividades de acordo com o interesse dos usuários que utilizam o sistema de recuperação da informação.

Ratificando a nossa constatação, Pinto Molina (1993) relata que a ação dos diferentes tipos de contextos tem a capacidade de mudar, trocar o significado das mensagens, atribuindolhe a ampla realidade da expressão, para que ele seja o retrato mais efetivo possível do cenário linguístico produzido.

Sob a perspectiva de Koch (2002), o contexto sociocognitivo é a interação entre contextos cognitivos, de modo que seus conhecimentos, de diversas origens, sejam parcialmente compartilhados. Esses conhecimentos - nomeados por "actantes sociais" - estão armazenados na memória para serem utilizados durante um intercâmbio verbal e referem-se ao conhecimento linguístico, conhecimento enciclopédico, conhecimento da situação comunicativa e de suas regras, conhecimento superestrutural, conhecimento estilístico, conhecimento de outros textos (intertextualidade). O uso desses conhecimentos prévios durante o processamento textual se realizará mediante estratégias de leitura de diferentes tipos.

O bibliotecário indexador, caracterizado como produtor do processo de compreensão, utiliza o conhecimento prévio que possui sobre sua ferramenta de trabalho (a política de indexação, as regras e os procedimentos do manual de indexação, a linguagem documental) e as reais necessidades dos usuários para realizar a análise de assuntos e, consequentemente, a representação temática. Por meio do conhecimento prévio textual e linguístico, ele terá capacidade de compreender a leitura para a elaboração dessa análise, auxiliado por seu conhecimento armazenado na memória, estruturas mentais que englobam o conhecimento linguístico, textual (estrutural) e o conhecimento de mundo, constituindo-se em experiências acumuladas utilizadas como estratégia de leitura e, consequentemente, de análise de assunto. 
No momento da representação da informação documental, a associação com a linguagem documental é citada por Fujita (2004) como uma estratégia profissional de leitura documental para a compreensão do conteúdo de um item informacional. A pesquisa de Boccato e Fujita (2006) complementa essa afirmação, demonstrado por um dos resultados obtidos, que o sujeito de pesquisa recorreu, por muitas vezes, ao seu conhecimento prévio especializado - identificado pela linguagem documental adotada pelo sistema - para a realização da identificação e seleção dos assuntos do documento analisado.

Todavia, ressaltamos que o recurso do bibliotecário indexador em recorrer ao seu conhecimento prévio especializado, isto é, à linguagem documental, muitas vezes prejudica a operação de identificação e seleção de conceitos pelo fato desses não comporem o corpus terminológico da linguagem e, dessa forma, não serem selecionados pelo bibliotecário indexador. Isso nos faz refletir sobre a necessidade de atualização constante das linguagens documentais adotadas por catálogos coletivos online de bibliotecas universitárias, em função da característica natural de evolução científica e do dinamismo e vanguardismo na geração de conhecimentos na universidade.

Outro fator importante é que, em muitos casos, essa condução privilegia a adoção da concepção de análise orientada para o conteúdo em detrimento a orientada para o usuário, o que não representa, por vezes, o desejo informacional do usuário. Em constatação empírica, a utilização da linguagem documental como conhecimento prévio especializado, no processo de análise de assunto, pôde ser vivenciada na realização dos nossos trabalhos profissionais como bibliotecária indexadora em catálogo coletivo online de áreas científicas especializadas de sistema público de bibliotecas universitárias.

Esse cenário é ratificado cientificamente com o estudo de observação elaborado por Borba (2003) sobre a associação da linguagem, quando utilizada como estratégia, ser um instrumento auxiliar do bibliotecário indexador na elaboração da tarefa de leitura, agilizando seu trabalho de indexação com maior compreensão e qualidade na identificação e seleção de conceitos. Com isso, a autora (Borba, 2003) verificou que as duas estratégias podem coexistir, contudo, sendo utilizadas de forma complementar em que a "validação pela linguagem documental" é a etapa final do processo da "associação com a linguagem" efetuada na etapa de análise de assunto. Além disso, a autora comprovou que o conhecimento prévio especializado é uma estratégia de leitura do contexto sociocognitivo do bibliotecário indexador, necessária para a compreensão de áreas científicas especializadas. 
As pesquisas de Boccato (2009) e de Boccato e Vitorini (2011) também evidenciam as constatações de Borba (2003) e apontam outros resultados de importância acerca do uso de linguagem documental de catálogos coletivos online, a partir do contexto sociocognitivo do indexador, aplicáveis no aprimoramento da prática profisisonal bibliotecária. São eles:

- realização inadequada da análise de assunto compromete a representação e o uso da linguagem com termos não correspondentes ao nível em que o assunto é efetivamente abordado pelo autor;

- reconhecimento por parte dos bibliotecários da importância do conhecimento sobre a área científica a ser representada pela linguagem;

- na representação da informação, a escolha do termo é realizada de acordo com o contexto da biblioteca em que o usuário está inserido;

- no processo de indexação, a incompatibilidade entre a linguagem documental adotada pelos catálogos online e a linguagem de busca do usuário compromete a atuação do bibliotecário na representação dos conteúdos documentais;

- $\quad$ necessidade da linguagem estar disponível no próprio sistema de recuperação da informação, isto é, na interface de entrada de dados (catalogação), para que a representação possa ser realizada a partir da própria linguagem em conexão com o formato bibliográfico adotado;

- $\quad$ necessidade do estabelecimento de uma política de indexação;

- $\quad$ necessidade da realização de cursos de capacitação em indexação, entre outros.

Diante do exposto, vimos que o contexto sociocognitivo do bibliotecário indexador é de suma importância para a adequada representação da informação em sistema de recuperação da informação na busca pelo campo de assunto.

\section{CONSIDERAÇÕES FINAIS}

Este estudo contextualiza-se entre o deslocamento do paradigma cognitivo para o paradigma social, que coloca o contexto do bibliotecário indexador no centro do processo informacional, caracterizado pela representação temática da informação de áreas científicas especializadas.

A construção deste estudo possibilitou-nos caracterizar e ratificar nosso ponto de vista sobre o contexto sociocognitivo ser um elemento a considerar no desenvolvimento do 
processo de indexação, a partir da leitura documental, visando à análise e a representação da informação condizente com as necessidades de busca do usuário.

Associados ao aspecto sociocognitivo, os aspectos físico e psicológico são fundamentais na formação do contexto do bibliotecário indexador, como variável de suma importância na construção desse processo.

A linguagem documental vista como o conhecimento prévio profissional e especializado do bibliotecário indexador, deve possibilitar a correspondência mais fiel possível dos conteúdos dos documentos e das necessidades informacionais dos usuários expressas por seu repertório linguístico natural.

Nessa vertente, as visões holística e coletiva dos bibliotecários indexadores são privilegiadas, contribuintes para a definição de um tratamento temático da informação e na modelagem e na construção de sistemas de recuperação da informação. A partir dessa concepção, a área de Ciência da Informação volta-se para uma dimensão teórica focada por abordagens interpretativas, centradas no aspecto semântico e no contexto social da informação, do bibliotecário indexador e do usuário.

\section{REFERÊNCIAS}

ALBRECHTSEN, H. Subject analysis and indexing from automated indexing to dominion analysis. The Indexer, London, v. 18, n. 4, p. 219-224, 1993.

BELKIN, N. J. Anomalous State of Knowledge as basis for information retrieval. The Canadian Journal of Information Science, Toronto, v. 5, p. 133-143, 1980.

BERNARD, J. A. Análisis y representación del conocimiento: aportaciones de la psicología cognitiva. Scire, Zaragoza, v.1, n.1, p. 57-80, en./jun. 1995.

BOCCATO, V. R. C. Avaliação do uso de linguagem documentária em catálogos coletivos de bibliotecas universitárias: um estudo sociocognitivo com protocolo verbal. 2009. 301 f. Tese (Doutorado em Ciência da Informação) - Faculdade de Filosofia e Ciências, Universidade Estadual Paulista, Marília, 2009a. Disponível em: $<$ http://www.athena.biblioteca.unesp.br/exlibris/bd/bma/33004110043P4/2009/boccato_vrc_d r_mar.pdf $>$. Acesso em: 13 maio 2011.

BOCCATO, V. R. C.; FUJITA, M. S. L. A atividade de indexação nas perspectivas das concepções de assunto: o protocolo verbal como instrumento de avaliação qualitativacognitiva. In: SEMINÁRIO NACIONAL DE BIBLIOTECAS UNIVERSITÁRIAS, 14., 2006, Salvador. Anais... Salvador: UFBa, 2006. 
BOCCATO, V. R. C.; FUJITA, M. S. L. Evaluation of indexing language used in collective catalogues of university libraries: a socio-cognitive study using verbal protocol. International Journal of Library and Information Science, Nairobi, v. 3, n. 8, p. 162-178, Sept. 2011. Disponível em: $<$ http://www.academicjournals.org/ijlis/PDF/pdf2011/Sept/Boccato\%20and\%20Fujita.pdf $>$. Acesso em: 22 nov. 2011.

BOCCATO, V. R. C.; FUJITA, M. S. L. The use of an indexing language in the catalogues of university libraries: a method of its evaluation by users based on a sociocognitive approach. In: GILCHRIST, A.; VERNAU, J. (Ed.). Facets of knowledge organization: proceedings of the ISKO UK Second Biennal Conference. Howard House, Emerald, 2012. p. 367-373.

BOCCATO, V. R. C.; VITORINI, E. F. Estudo do uso de linguagem documentária em catálogos coletivos de bibliotecas universitárias: uma avaliação qualitativa-sociocognitiva pela perspectiva do bibliotecário indexador. In: CONGRESSO BRASILEIRO DE BIBLIOTECONOMIA, DOCUMENTAÇÃO E CIÊNCIA DA INFORMAÇÃO, 24., 2011, Maceió. Anais.... São Paulo: FEBAB, 2011. Disponível em: $<$ http://febab.org.br/congressos/index.php/cbbd/xxiv/paper/view/40/658 $>$. Acesso em: $08 \mathrm{dez}$. 2011.

BORBA, E. A. Leitura para indexação: o uso da linguagem documentária como estratégia específica do leitor profissional. 2003. 65 f. Monografia (Graduação em Biblioteconomia) Faculdade de Filosofia e Ciências, Universidade Estadual Paulista, Marília. 2003.

BUSH, V. As we may think. The Atlantic Monthly, Boston, v. 176, n. 1, p. 101-108, 1945. Disponível em: $<$ http://www.theatlantic.com/unbound/flashbks/computer/bushf.htm $>$. Acesso em: 08 set. 2008.

CAPURRO, R. Epistemologia e ciência da informação. In: ENCONTRO NACIONAL DE PESQUISA EM CIÊNCIA DA INFORMAÇÃO - ENANCIB, 5., 2003. Belo Horizonte. Anais... Belo Horizonte: UFMG, 2003.

FINO, C. N. Convergência entre a teoria de Vygotsky e o onstrutivismo/construcionismo. Disponível em: $\leq$ http://www.uma.pt/carlosfino/Documentos/Draft Convergencia Vygotsky construtivismo construcionismo.pdf $>$. Acesso em: 19 mar. 2008.

FROHMANN, B. Rules of indexing: a critique of mentalism in information retrieval theory. Journal of Documentation, London, 1990, v. 46, n. 2, p. 81-101.

FUJITA, M. S. L. A leitura documentária na perspectiva de suas variáveis: leitor-textocontexto. DataGramaZero - Revista de Ciência da Informação, v. 5, n. 4, ago. 2004. Disponível em: < http://www.datagramazero.org.br $>$ Acesso em: 19 ago. 2008.

FUJITA, M. S. L. Aspectos evolutivos das bibliotecas universitárias em ambiente digital na perspectiva da rede de bibliotecas da UNESP. Informação \& Socidade: estudos, João Pessoa, v. 15, n. 2, p. 97-112, jul./dez. 2005.

FUJITA, M. S. L.; RUBI, M. P. Um modelo de leitura documentária para a indexação de artigos científicos: princípios de elaboração e uso para a formação de indexadores. 
DataGramaZero - Revista de Ciência da Informação, Rio de Janeiro, v .7, n. 3, jan. 2006. Disponível em: < http://www.dgz.org.br>. Acesso em: 12 dez. 2008.

FUJITA, M. S L.; NARDI, M. I. A.; SANTOS, S. dos. A leitura em análise documentária. Transinformação, Campinas, v. 10, n. 3, p. 13-31, set./dez. 1998.

FUJITA, M. S. L.; RUBI, M. P.; BOCCATO, V. R. C. O contexto sociocognitivo do catalogador em bibliotecas universitárias: perspectivas para uma política de tratamento da informação documentária. DataGramaZero - Revista de Ciência da Informação, Rio de Janeiro, v. 10, n. 2, abr. 2009. Disponível em: <http://www.datagramazero.org.br $>$. Acesso em: 14 abr. 2009.

GIASSON, J. A compreensão na leitura. Lisboa: Asa, 1993.

HJØRLAND, B. Epistemology and the socio-cognitive perspective in information science. Journal of the American Society for Information Science and Technology, New York, v. 53, n. 4, p. 257- 270, 2002.

HJØRLAND, B; ALBRECHTSEN, H. Toward a new horizon in information science: domain-analysis. Journal of the American Society for Information Science, New York, v.46, n.6, p.400-425, 1995.

INGWERSEN, P. Conceptions of information science. In: VAKKARI, P., CRONIN, B. (Ed.). Conceptions of library and information science: historical, empirical and theoretical perspectives. London: Taylor Graham, 1992. p. 299-312.

INGWERSEN, P. Information retrieval interaction. Los Angeles: Taylor Graham, 2002. 246 p. Disponível em: <http://www.db.dk/pi/iri>. Acesso em: 4 nov. 2007.

JACOB, E. K.; SHAW, D. Socio-cognitive perspectives on representation. In: WILLIANS, M. E. (Ed.). Annual Review of Information Science and Technology. Medford: Information Today for American Society for Information Science, 1998. v. 33, p.131-185.

KOCH, I. G. V. Desvendando os segredos do texto. São Paulo: Cortez, 2002.

NASCIMENTO, D. M. A abordagem sócio-cultural da informação. Informação \& Sociedade: estudos, João Pessoa, v. 16, n. 2, p.25-35, jul./dez. 2006. Disponível em: $<$ http://www.ies.ufpb.br/ojs2/index.php/ies/article/view/477/1474 > . Acesso em: 25 maio 2008 .

NAVES, M. N. L. Estudo dos fatores interferentes no processo de análise de assunto. Perspectivas em Ciência da Informação, Belo Horizonte, v. 6, n. 2, p. 189-203, jul./dez. 2001.

NEVES, D. A. Ciência da informação e cognição humana: uma abordagem do processamento da informação. Ciência da Informação, Brasília, v. 35, n. 1, p. 39-44, jan./abr. 2006.

NEVES, D. A. de B. Metacognição [,] informação e conhecimento: pensando em como pensar: Recife: Néctar, 2011. 
OLIVEIRA, D. S. de. Estratégias para o ensino de indexação: o uso do protocolo verbal interativo como recurso pedagógico de indexadores aprendizes. 2005. $225 \mathrm{f}$. Monogrfia (Graduação em Biblioteconomia) - Faculdade de Filosofia e Ciências, Universidade Estadual Paulista, Marília, 2005.

OLSON, H. A.; BOLL, J. J. Subject analysis in online catalogs. $2^{\text {nd }}$ ed. Englewood: Libraries Unlimited, 2001.

PAPERT, S. Mindstorms: children, computers, and powerful ideas. New York: Basic Books, 1990.

PINTO MOLINA, M. Análisis documental: fundamentos y procedimientos. 2. ed. rev. y aum. Madrid: EUDEMA, 1993.

RUBI et al. Política del tratamiento de la información documentaria en bibliotecas universitarias: estudio diagnóstico del contexto en la perspectiva del catalogador y del usuario. In: GARCÍA MARCO, F. J. (Ed.). Avances y perspectivas en sistemas de información y documentación en I entorno digital, IBERSID 2007. Zaragoza: Universidad de Zaragoza, 2008. p. 71-77.

SHERA, J. H. Putting knowledge to work. In: organization of knowledge. Hamden: Archon Books, 1965.

(Ed.). Libraries and the

STERNBERG, R. J. Psicologia cognitiva. Tradução de Roberto Cataldo Costa. 4. ed. Porto Alegre: Artmed, 2008.

VYGOTSKY, L. S. A formação social da mente: o desenvolvimento dos processos psicológicos superiores. São Paulo: Martins Fontes, 1989. 